\title{
Mid-Term Clinical Outcome of Patients Undergoing Coronary Artery Bypass Grafting with Valvulotomized Vein Grafts
}

\author{
Selcuk Anli, ${ }^{1}$ Afsaneh Karimian-Tabrizi,${ }^{1}$ Anton Moritz, $\mathrm{MD}, \mathrm{PhD},{ }^{1}$ Nadejda Monsefi, $\mathrm{MD}^{2}$ \\ ${ }^{1}$ Department of Thoracic and Cardiovascular Surgery, University Hospital, Frankfurt/Main, Germany; ${ }^{2}$ Department of \\ Cardiothoracic Surgery, Heart Center Siegburg, Siegburg, Germany
}

\section{ABSTRACT}

Background: The lower patency rate of vein grafts (VG) in comparison to arterial grafts may be related to vein valves, which favor turbulences and thrombosis that lead to graft failure. The aim of this study was to determine the outcome of patients with valvulotomized VG after coronary artery bypass grafting (CABG) procedure.

Methods: From 2007 to 2014, 233 patients with a mean age of $67 \pm 9$ years had CABG or combined CABG and valve procedures. Valvulotomized saphenous VG and arterial grafts were used. Clinical follow-up and outcome were evaluated after $6.3 \pm 2$ years. The graft patency was rated with multislice computed tomography in 57 patients and coronary angiography in 29 patients $3.1 \pm 2$ years postoperatively.

Results: Overall, 168 patients had segregated CABG surgery, and 65 patients received additional procedures, with mean $2.7 \pm 1$ arterial and $1.5 \pm 0.7$ venous anastomoses. The 30 -day-mortality in isolated CABG patients was $2 \%$. Survival at five years was $80 \%$. Major adverse cardiac and cerebrovascular events (MACCE) free rate at five years was $80 \%$. At the last follow up (mean 6.3 years), 94\% of the patients were in Canadian Cardiovascular Society (CCS) class 0 . The quote of patent valvulotomized VG was $96.1 \%$ compared to a patency rate of $96.7 \%$ for the arterial grafts in the subgroup undergoing angiography or computed tomography of the heart.

Conclusion: Our data demonstrate good mid-term results of graft patency, and comparable clinical results in patients undergoing CABG with valvulotomized VG. A longer follow-up period and a higher number of bypass graft imaging examinations are necessary to affirm our results.

\section{INTRODUCTION}

One of the biggest advantages of coronary artery bypass grafting (CABG) is the longevity and patency of grafts. The Syntax trial showed that CABG is the norm of care for patients with multi-vessel or left main coronary artery disease, with

Received Decmeber 31, 2017; received in revised form May 5, 2018; accepted May 7, 2018.

Correspondence: Nadejda Monsefi, MD, Department of Cardiothoracic Surgery, Heart Center Siegburg, Ringstr. 49, 53721 - Siegburg, Germany; 004916096500723, fax:0049-2241182932 (e-mail:nadi037@aol.com). superior results in terms of major adverse cardiac and cerebrovascular events (MACCE) compared to percutaneous coronary intervention (PCI) [Mohr 2013]. In the Syntax trial, a large number of patients had a bypass operation using an internal thoracic artery and additional saphenous vein (SV) graft. During the last 17 years, several studies report an increased usage of arterial grafts for CABG, due to its survival benefit [Glineur 2012; Taggart 2001; Calafiore 2000; Lytle 1999].

The ideal choice for the second graft in CABG is still a controversial issue, as studies on this topic with randomized trials and a significant number of patients are lacking. A 90\% patency rate for VG at five years is described in a randomized study by Hayward and colleagues [Hayward 2010]. However, the disadvantages of venous conduits are obvious, including diameter mismatch and vein valves [Mills 1989]. Mills characterizes the vein valves as "bad guys" in CABG that might have an influence on hemodynamic relevant narrowing [Mills 1989]. The work of Lajos and coworkers may show enhanced patency of valvulotomized VG in "horseshoe grafts" [Lajos 2007].

In this study we aimed to analyze patency data and clinical outcomes of patients who received CABG with valvulotomized vein graft (VG) at the University Hospital Frankfurt am Main.

\section{MATERIALS AND METHODS}

CABG with valvulotomized VG was performed on 233 patients from 2007 to 2014 at the University Hospital Frankfurt am Main. During this period, 4737 isolated CABG and 1142 CABG and concomitant procedures were performed. Patients who received valvulotomized VG in our center were included. All VGs were valvulotomized except when they were already free of vein valves. The preoperative patient data are characterized in Table 1 . Patients were an average of $67 \pm$ 9 years old.

The area of the anterior wall was always provided with the left internal mammary artery (LIMA). A valvulotomized VG was bypassed to the right coronary artery (RCA). The circumflexus area was revascularized depending on graft disposability (with radial artery [RA], or right internal mammary artery [RIMA]), and the risk criterion of the patient. The RA was used when the target vessel had a profound stenosis (>80\%). We avoided bilateral use of internal mammary artery (BIMA) in patients with chronic obstructive pulmonary disease (COPD) or insulin dependent diabetes mellitus. Retrospective and follow up clinical data were collected. Our institutional ethics committee permitted the study. 
Table 1. Patient Characteristics

\begin{tabular}{lc}
\hline Variable list & \\
\hline $\mathrm{n}(\%)$ & 233 \\
Age & $67 \pm 9$ \\
Female & 27 \\
Male & 206 \\
CCS II-III & $205(89 \%)$ \\
NYHA II -III & $211(91 \%)$ \\
Former myocardial infarction & $34(15 \%)$ \\
Cardiogenic shock & $2(0.9 \%)$ \\
PCl/stent & $42(18 \%)$ \\
Hypertension & $191(82 \%)$ \\
Hypercholesterolemia & $106(45 \%)$ \\
COPD & $22(9 \%)$ \\
pad & $18(8 \%)$ \\
Renal insufficiency & $40(17 \%)$ \\
Diabetes mellitus & $73(31 \%)$ \\
Coronary artery disease & \\
Left main stenosis & $87(37 \%)$ \\
One-vessel disease & $6(3 \%)$ \\
Two-vessel disease & $27(11 \%)$ \\
Three-vessel disease & $200(86 \%)$ \\
EF (\%) & $54 \pm 1$ \\
Previous heart operation & $4(2 \%)$ \\
\hline & \\
\hline
\end{tabular}

CCS indicates Canadian Cardiovascular Society Angina Classification; NYHA, New York Heart Association classification; PCl, percutaneous coronary intervention; COPD, chronical obstructive pulmonary disease; pad, peripheral artery disease; EF, ejection fraction.

\section{Operative Technique}

The standard approach in CABG was median sternotomy. Preparation of IMA was done as a veno-arterial pedicle [Wimmer-Greinecker 1999]. The artery was rinsed with spasmolytic solution. The radial artery (RA) harvesting technique has been published elsewhere [Risteski 2006]. The great SV was taken gently from the lower limb, preserving the enclosed adventitia. The vein preparation has been described elsewhere [Monsefi 2016]. Cannulation of the vein at the distal end was performed, and tagging of venous valves was done by probing. Then, valvulotomy was undertaken using valve scissors (Ulrich medical, Ulm, Germany) before distal anastomoses were performed with the reversed vein [Monsefi 2016].

In detail, the venous graft harvesting was performed, the vein was removed, and the vein valves were then valvulotomized with a small valvulotomy scissor that was inserted gently into the inflated vein. When vein valves were present, their resistance could be felt when penetrating them gently

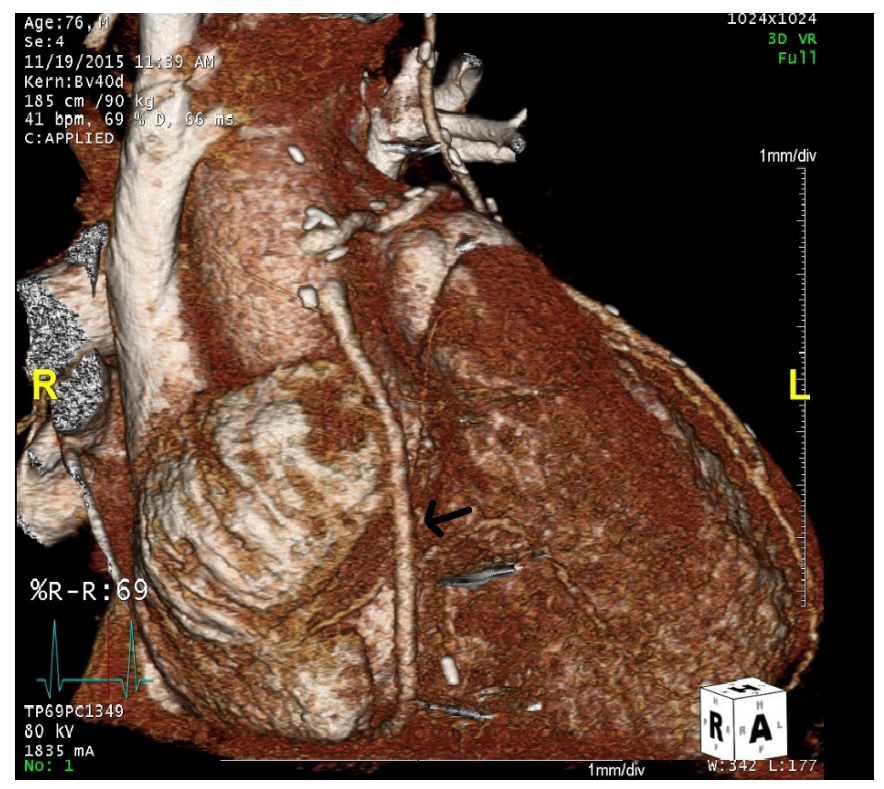

Figure 1. Computer tomography (CT) of the heart, with black arrow indicating the patent valvulotomized venous bypass graft to the right coronary artery (RCA).

with the valvulotomy scissors. When they were cut, the scissors were pushed forward in the vein until the complete length of the vein was valvulotomized. The vein flush solution consisted of a buffered saline solution loaded with papaverine and heparin.

The decision of placing the conduits to the recipient coronary was dependent on the amount of vessel disease, graft availability, and the grade of stenosis of the coronary vessel. LIMA was always used for the left anterior wall revascularisation (LAD). Another arterial graft (RIMA or radial artery) was used for the next territory (ramus circumflexus [RCX] or right coronary artery [RCA]). The radial artery was only used when the destination vessel had profound stenosis $(>80 \%)$. For the third territory, the valvulotomized vein was used (RCX or RCA). Typically, we applied two arterial and one venous graft for CABG in cases of three diseased vessels.

The majority of CABG cases $(n=219,94 \%)$ were performed on-pump. Calafiore solution was applied for myocardial protection [Calafiore 1996]. Distal anastomoses were done with $7 / 0$ or $8 / 0$ Prolene (Ethicon, Norderstedt). Lastly, proximal anastomoses to the aorta were finalized.

\section{Postoperative Follow- Up}

Clinical follow up $(6.3 \pm 2$ years $)$ of the patients was assessed by phone call or letter, and was completed in $99 \%$ of patients. NYHA and CCS statuses were evaluated. Survival and MACCE were analyzed. MACCE was specified as all sources of death, myocardial infarction, cerebrovascular incident, and recurrent revascularization. Coronary angiography results from assigning cardiologists were also collected. In cases of atypical chest pain, patients were examined with multislice computed tomography of the heart (MSCT) for testing graft patency (Figure 1). 
Table 2. Perioperative Results and Surgical Procedures

\begin{tabular}{|c|c|}
\hline Variable list & \\
\hline On pump & $219(94 \%)$ \\
\hline CPB time mean (min) & $151 \pm 42$ \\
\hline Cross-clamp time mean (min) & $102 \pm 31$ \\
\hline Number of anastomoses (mean) & $4.2 \pm 1$ \\
\hline Arterial & $2.7 \pm 1$ (mean) \\
\hline Venous & $1.5 \pm 0.7$ (mean) \\
\hline Number of grafts (number of anastomoses) & 933 \\
\hline LIMA to anterior wall & $\begin{array}{c}\text { 215, with } 135 \text { sequential } \\
\text { (total } 350 \text { ) }\end{array}$ \\
\hline RIMA to $C X$ & $\begin{array}{c}\text { 113, with } 62 \text { sequential } \\
\text { (total } 175)\end{array}$ \\
\hline Radial artery to $\mathrm{CX}$ & $\begin{array}{c}\text { 40, with } 20 \text { sequential } \\
\text { (total } 60 \text { ) }\end{array}$ \\
\hline Saphenous vein graft total & 348 \\
\hline Saphenous vein graft to RCA & $\begin{array}{c}\text { 195, with } 55 \text { sequential } \\
\text { (total } 250 \text { ) }\end{array}$ \\
\hline Saphenous vein graft to $\mathrm{CX}$ & $\begin{array}{c}\text { 66, with } 32 \text { sequential } \\
\text { (total } 98 \text { ) }\end{array}$ \\
\hline \multicolumn{2}{|l|}{ Concomitant procedures in 65 patients } \\
\hline Aortic valve replacement & 25 \\
\hline Mitral valve repair & 11 \\
\hline Tricuspid valve repair & 6 \\
\hline Aorta ascendens replacement & 8 \\
\hline Ablation & 15 \\
\hline ICU stay (d) & $2 \pm 3$ \\
\hline Ventilation time $(\mathrm{h})$ & $20 \pm 27$ \\
\hline Neurological event (stroke) & $1(0.4 \%)$ \\
\hline Myocardial infarction & $1(0.4 \%)$ \\
\hline Reangiography/stent & $1(0.4 \%)$ \\
\hline Reoperation (bypass revision) & $1(0.4 \%)$ \\
\hline 30-d mortality (all procedures) & $10(4 \%)$ \\
\hline 30-d mortality (isolated CABG) & $5(2 \%)$ \\
\hline
\end{tabular}

CPB indicates cardiopulmonary bypass; LIMA, left internal mammary artery; RIMA, right internal mammary artery; ICU, intensive care unit; CX, circumflexus; RCA, right coronary artery; ICU, intensive care unit; $C A B G$, coronary artery bypass graft.

\section{Statistical Analysis}

Statistical analysis was performed using BIAS 11.06 software (Frankfurt, Germany). Continuous parameters are indicated as mean \pm standard deviation, and categorical information as numbers and percentages. The survival curve and the MACCE free curve were evaluated using the Kaplan-Meier method. For comparison of the patency between the conduits, the chi-square or fisher's exact test was applied.
Table 3. Follow-Up Data

\begin{tabular}{|c|c|}
\hline Myocardial infarction & $2(1 \%)$ \\
\hline Coronary reangiography & $29(12 \%)$ \\
\hline $\operatorname{CCS} 0$ & 150 (94\%) \\
\hline CCSI & $9(5 \%)$ \\
\hline NYHA I & $133(83 \%)$ \\
\hline NYHA II & $24(15 \%)$ \\
\hline NYHA III & $2(1 \%)$ \\
\hline Neurological event (stroke) & $4(2 \%)$ \\
\hline Reoperation & 0 \\
\hline Late mortality & $63(28 \%)$ \\
\hline CT scan of the heart & $57(25 \%)$ \\
\hline \multicolumn{2}{|l|}{$\begin{array}{l}\text { Results of } 29 \text { reangiographies and } 57 \mathrm{CT} \text { scans } \\
\text { in } 86 \text { patients }\end{array}$} \\
\hline Patency rate of venous $B G$ to the $R C A$ & $94.8 \%$ (4/77 occluded) \\
\hline Patency rate of venous $B G$ to the $C X$ & $94.1 \%(1 / 17$ occluded $)$ \\
\hline Patency rate of venous anastomoses & $95.7 \%$ (5/117 occluded) \\
\hline Patency rate of all venous BG & $96.1 \%(5 / 94$ occluded $)$ \\
\hline Patency rate of LIMA graft to anterior wall & $97.6 \%(2 / 84$ occluded $)$ \\
\hline Patency rate of RIMA graft to CX & $94.2 \%(3 / 52$ occluded $)$ \\
\hline Patency rate of radial artery graft to $\mathrm{CX}$ & $100 \%(0 / 14$ occluded $)$ \\
\hline Patency rate of arterial anastomoses & $97.9 \%(5 / 242$ occluded $)$ \\
\hline Patency rate of arterial BG & $96.7 \%(5 / 150$ occluded $)$ \\
\hline
\end{tabular}

(mean $6.3 \pm 2$ years; $99 \%$ completed)

CCS indicates Canadian Cardiovascular Society Angina Classification;

NYHA, New York Heart Association classification; TND, temporary neurological deficit; $\mathrm{CT}$, Computed tomography; BG, bypass graft; $\mathrm{RCA}$, right coronary artery; $\mathrm{CX}$, circumflexus.

\section{RESULTS}

As displayed in Table 2, 168 patients underwent single CABG, and 65 patients had concomitant procedures. The mean number of anastomoses was $4.2 \pm 1$, with a trend for increased arterial anastomoses $(2.7 \pm 1)$. There was one case of myocardial infarction perioperatively due to bypass kinking (LIMA-LAD) that lead to early bypass revision. There were no operative deaths. The 30-day-mortality was $2 \%$ $(\mathrm{n}=5)$ in isolated CABG, and $4 \%(\mathrm{n}=10)$ in total: three patients suffered from multi organ failure (two of them urgent cases due to acute coronary syndrome), three died unexpectedly after uneventful recovery, two died of heart failure (one was in cardiogenic shock preoperatively), one patient suffered sepsis due to pneumonia, and one died of brain death due to stroke and cerebral edema.

Follow up data are presented in Table 3. In the follow up period, 63 patients died: 16 patients died of cancer, eight suffered from sepsis, six had terminal renal failure, four had a fatal fall, two died of multi organ failure, one died of sustained 


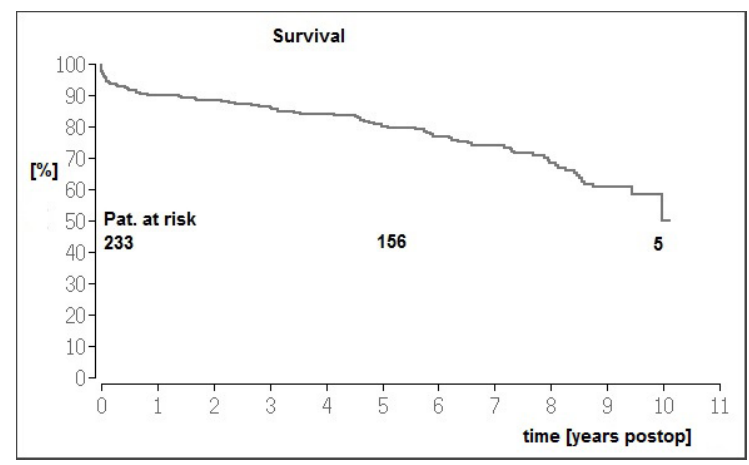

Figure 2. Kaplan-Meier-curve for survival.

rupture of a duodenal ulcer, two had ischemia of the bowel, two sustained fulminant stroke, three suffered from pneumonia, one from creutzfeldt jakob disease, and one from pulmonary edema. Ten patients had cardiac-related events like heart failure $(\mathrm{n}=7)$, myocardial infarction $(\mathrm{n}=1)$, cardiac arrest $(\mathrm{n}=1)$, and low cardiac output syndrome $(\mathrm{n}=1)$. In seven patients, the cause of death was unidentified. Kaplan-Meier survival at five years was $80 \%$ (Figure 2). MACCE free rate at five years was $80 \%$, and $45 \%$ at ten years (Figure 3 ).

Twenty-nine re-angiographies and 57 MSCT scans were used for the assessments of graft patency in 86 patients; five patients had an occlusion of the VG. Two patients had an occlusion of the LIMA graft to the anterior wall, and three patients had an occlusion of the RIMA graft to the RCX. Two patients received stents in the RCX territory, one because of de-novo stenosis, and the other because of RIMA graft dysfunction. We analyzed a $96.1 \%$ patency rate for the valvulotomized VG with $94.8 \%$ for the RCA territory; specifically, a $92.6 \%$ patency rate (4/54 occluded) for VG to RCA, $100 \%$ ( $0 / 23$ occluded) for VG to PDA $(P=.23)$, and $96.7 \%$ for the arterial grafts in the subgroup $(\mathrm{n}=86) 3.1 \pm 2$ years postoperatively. At the last follow up (mean of 6.3 years), $94 \%$ of the patients were in CCS class 0 , and $83 \%$ were in New York Heart Association (NYHA) class I.

We compared the patency rates of the different conduits and found that there was no significant difference: Arterial versus venous $B G$ patency, $P=.33$; RIMA versus LIMA graft patency, $P=.28$; radial artery versus RIMA graft patency, $P$ $=.48$; radial artery versus LIMA graft patency, $P=.73$; radial artery versus venous graft patency, $P=.49$; RIMA versus venous graft patency, $P=.59$; LIMA versus venous graft patency, $P=.27$.

\section{DISCUSSION}

The Syntax trial has emphasized that CABG should be the standard of treatment for patients with complex lesions, as MACCE was significantly better than PCI in their patient group [Mohr 2013]. Although there is a trend towards full arterial revascularization, the ideal choice for the second graft in CABG is still a controversial issue [Buttar 2017; Naik 2003]. Athanasiou and colleagues presented a meta-analysis of 35 studies that showed a superiority in mid-term (range

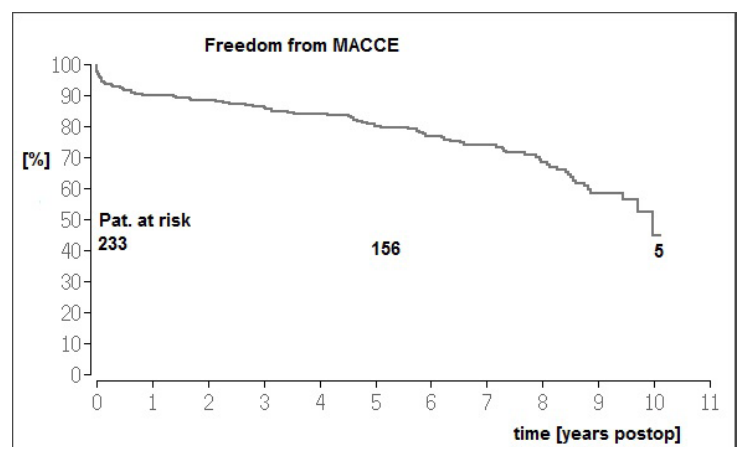

Figure 3. Freedom from major-adverse-cardiac-and-cerebrovascularevents (MACCE) curve.

$51 \%-97 \%)$ and long-term patency (85\%-94\%) for RA conduits in comparison to SV $(59 \%-91 \%$ at mid-term and $64 \%$ $91 \%$ at long-term), despite similar early patency rates of both conduits $(50 \%-100 \%$ for RA and $60 \%-100 \%$ for SV conduits) [Athanasiou 2011].

In the small cohort of our study, the mid-term $(3.1 \pm 2$ years) patency rate of valvulotomized VG was $96.1 \%$, versus $100 \%$ in radial artery grafts (Table 3). This is comparable to Athanasiou's findings. Supporters of RA grafts advocate the minimal intimal proliferation and adaption to blood flow compared to SV grafts [Joannides 1995]. However, other studies suggest the use of SV conduits over RA grafts because of better mid-term patency rates of SV versus RA (64\% versus $51.3 \%$ at a mean of 565 days follow-up) [Khot 2004]. The mid-term patency results of RIMA bypass grafting is $94.2 \%$ in our study, which is similar to the patency rate of valvulotomized VG $(96 \%)$.

Glineur and colleagues examined 152 patients with coronary angiography, and reported the dysfunction of $25.3 \%$ of RIMA grafts six months postoperatively. In particular, when RIMA was anastomosed to the intermediate branch or RCA, the prognosis was inferior [Glineur 2009]. In the small cohort of our study (86 patients who received CT scan of the heart/ coronaries or reangiography), RIMA graft patency was inferior in comparison to RA and LIMA graft patency, and similar to that of the SV graft at $3.1 \pm 2$ years follow up (Table 3).

Mukherjee et al found 226 articles on the topic of whether the RIMA achieves an outcome superior to the saphenous VG for revascularization of the RCA. In summary, considering methodological limits and differences in evidence, they showed that the saphenous VG offers an improved outcome for revascularization of the RCA when compared to RIMA BG, and better results in patency, recurrent revascularization, and cardiovascular complication [Mukherjee 2012]. Hayward and colleagues presented data of a randomized trial that compared the patency rate of arterial (RA or RIMA) and saphenous VG as a second graft: At a mean 5.5 year follow-up angiography in mostly asymptomatic patients, the choice of arterial or venous graft for the second conduit did not significantly influence patency [Hayward 2010].

Shah and colleagues investigated the mid-term (3 years) graft patency rates of bypass grafts in randomized studies: the patency rate of the saphenous VG was $90 \%$, similar to 
that of the RA graft (91\%) when used for the second best region [Shah 2005]. These findings are comparable to our data (Table 3). The valvulotomized VG had similar mid-term patency rates $(96.1 \%)$ compared to that of arterial grafts in our study (100\% for RA and $94.2 \%$ for RIMA). A few studies describe the merit of valvulotomized VG: Thubrikar described the pressure trap character as a possible cause of vein graft stenosis in an experimental survey. He showed that the veins opened and closed every cardiac circuit when the venous flow rate decreased under $30 \mathrm{~mL} / \mathrm{min}$, and that the blood flow in the segment distal to the venous valve stopped in each cycle [Thubrikar 1994]. Molina used valvulotomized saphenous VG in CABG and described a midterm patency rate of $90 \%$ (mean 3.5 years) for valvulotomized VG [Molina 1989]. Lajos et al showed an improvement of patency in valvulotomized "horseshoe grafts" [Lajos 2007].

In a former study, we demonstrated that flow in the venous bypass graft to the RCA increased significantly after valvulotomy, which supports the assumption noted above $(+20.2$ $\mathrm{mL} / \mathrm{min} ; P=.02$ ) [Monsefi 2016]. Of course, it is necessary to mention the potential detrimental effect of valvolotomy if it is performed incorrectly. If pushing the valvulotomy scissors in the vein by force, endothelial disruption and graft tear/ trauma could occur, which could promote early graft closure. Our experience with valvulotomized saphenous VGs presents a patency rate of $96.1 \%$, versus $96.7 \%$ for the arterial grafts after $3.1 \pm 2$ years postoperatively in the subgroup $(n=86)$. In this subgroup, valvulotomized vein grafts have analog midterm patency as arterial grafts. However, the patency rates between the different conduits mentioned in the results section did not differ signinificantly in our study. We think that a longer follow up period and a higher sample size is necessary to reveal the long term effects of valvulotomy, and its effect on patency rate.

Valvulotomy is feasible, and seems to be an effective surgical technique to improve patency rate. The MACCE free rate was $80 \%$ at five years in our study, which is comparable to other reported trials [Mohr 2013]. However, long-term follow-up investigations and a larger volume of MSCTs and angiographies are needed to confirm our results.

\section{STUDY LIMITATIONS}

About 86 of 233 (37\%) patients in this study had a CT scan or coronary re-angiography of the heart. A higher volume of valvulotomized vein grafts cases, and more CT scans with a longer follow up period could provide clearer and more reliable results. Another limitation is the surgeons' experience, which plays an important role and affects also outcome. Finally, a randomized controlled survey or a propensity matched analysis that distinguishes between valvulotomized and non-valvulotomized VG would provide interesting data.

\section{REFERENCES}

Athanasiou T, Saso S, Rao C, et al. 2011. Radial artery versus saphenous vein conduits for coronary artery bypass surgery: forty years of competition - which conduit offers better patency? A systematic review and meta-analysis. Eur J Cardiothorac Surg 40:208-20.

Buttar SN, Yan TD, Taggart DP, et al. 2017. Long-term and short-term outcomes of using bilateral internal mammary artery grafting versus left internal mammary artery grafting: a meta-analysis. Heart 103:1419-1426.

Calafiore AM, Contini M, Vitolla G, et al. 2000. Bilateral internal thoracic artery grafting: long-term clinical and angiographic results of in situ versus Y grafts. J Thorac Cardiovasc Surg 120:990-6.

Calafiore AM, Teodori G, Bosco G, et al. 1996. Intermittent antegrade warm blood cardioplegia in aortic valve replacement. J Card Surg 11:348-354.

Glineur D, D’hoore W, Price J, et al. 2012. Survival benefit of multiple arterial grafting in a 25 -year single institutional experience: the importance of the third arterial graft. Eur J Cardiothorac Surg 42:284-90

Glineur D, Hanet C, D'hoore W, et al. 2009. Causes of non-functioning right internal mammary used in a Y-graft configuration: insight from a 6-month systematic angiographic trial. Eur J Cardiothorac Surg 36:129-136.

Hayward PA, Gordon IR, Hare DL, et al. 2010. Comparable patencies of the radial artery and right internal thoracic artery or saphenous vein beyond 5 years: results from the Radial Artery Patency and Clinical Outcomes trial. J Thorac Cardiovasc Surg 139:60-5.

Joannides R, Haefeli W, Linder L, et al. 1995. Nitric oxide is responsible for flow-dependent dilatation of human peripheral conduit arteries in vivo. Circulation 91:1314-9.

Khot UN, Friedman DT, Pettersson G, et al. 2004. Radial artery bypass grafts have an increased occurrence of angiographically severe stenosis and occlusion compared with left internal mammary arteries and saphenous vein grafts. Circulation 109:2086-91.

Lajos TZ, Robicsek F, Thubrikar M, et al. 2007. Improving patency of coronary conduits "valveless" veins and/or arterial grafts. J Card Surg 22:170-7.

Lytle BW, Blackstone EH, Loop FD, et al. 1999. Two internal thoracic artery grafts are better than one. J Thorac Cardiovasc Surg 117:855-72.

Mills NL. 1989. Saphenous vein graft valves: "The bad guys". Ann Thorac Surg 48:613-4.

Mohr FW, Morice MC, Kappetein AP, et al. 2013. Coronary artery bypass graft surgery versus percutaneous coronary intervention in patients with three-vessel disease and left main coronary disease: 5-year follow up of the randomized, clinical SYNTAX trial. Lancet 381:629-38.

Molina JE. 1989. Nonreversed saphenous vein grafts for coronary artery bypass grafting. Ann Thorac Surg 48:624-7.

Monsefi N, Zierer A, Honarpisheh G, et al. 2016. One-year patency of valvulotomized vein grafts is similar to that of arterial grafts. Thorac Cardiovasc Surg 64:204-10.

Mukherjee D, Cheriyan J, Kourliouros A, et al. 2012. Does the right internal thoracic artery or saphenous vein graft offer superior revascularization of the right coronary artery? Interact Cardiovasc Thorac Surg 15:244-7.

Naik MJ, Abu-Omar Y, Alvi A, et al. 2003. Total arterial revascularisation as a primary strategy for coronary artery bypass grafting. Postgrad Med J 79:43-8.

Risteski PS, Akbulut B, Moritz A, et al. 2006. The radial artery as a conduit for coronary artery bypass grafting: review of current knowledge. Anadolu Kardiyol Derg 6:153-62.

Shah PJ, Bui K, Blackmore S, et al. 2005. Has the in situ right internal 
thoracic artery been overlooked? An angiographic study of the radial artery, internal thoracic arteries and saphenous vein graft patencies in symptomatic patients. Eur J Cardiothorac Surg 27:870-5.

Taggart DP, D`Amico R, Altman DG. 2001. Effect of arterial revascularisation on survival: a systematic review of studies comparing bilateral and single internal mammary arteries. Lancet 358:870-5.
Thubrikar MJ, Robicsek F, Fowler BL, et al. 1994. Pressure trap created by vein valve closure and its role in graft stenosis. J Thorac Cardiovasc Surg 107:707-16.

Wimmer-Greinecker G, Yosseef-Hakimi M, Rinne T, et al. 1999. Effect of internal thoracic artery preparation on blood loss, lung function, and pain. Ann Thorac Surg 6:153-162. 